\title{
APPLICATION OF THE PEDICLED M. LATISSIMUS DORSI FLAP FOR TRUNK RECONSTRUCTIONS
}

\author{
Daniel Yankov, Yolanda Zayakova, Hristo Hristov, Natalia Nenkova \\ Division of Burns, Plastic, Reconstructive and Aesthetic Surgery, Department of Surgery, \\ Naval Hospital of Varna, Military Medical Academy of Sofia
}

\begin{abstract}
PURPOSE: M. latissimus dorsi flap is one of the most commonly used pedicled flaps in plastic surgery. It can be based either on the dominant thoracodorsal vessels, or, as a reverse flap, on its secondary segmental pedicles. The purpose of this paper is to evaluate our experience with pedicled flaps from $m$. latissimus dorsi for trunk reconstructions.

MATERIAL AND METHODS: In the present study, we applied eight flaps on 7 patients: four flaps for breast reconstruction, one flap for postmastectomy radiation wound treatment, one flap to cover a defect on the anterior thoracic wall caused by toxic skin necrosis, one flap to correct axillary skin contracture after deep burn injury, and one for lumbar reconstruction after malignant melanoma radical excision.

RESULTS: In the present paper, two cases with application of this flap were reported to illustrate the stages of the surgical technique. All the flaps were vital and adapted normally. Narrow partial skin necrosis and donor scar depression were observed in the largest skin-muscle flap only.

CONCLUSION: M. latissimus dorsi pedicled flaps are reliable source for trunk reconstructions. They may transfer abundant plastic material to compensate tissue deficit of different etiology. The risk of complications is insignificant, whereas the patients' quality of life is considerably improved.
\end{abstract}

Key words: musculus latissimus dorsi, pedicled flap, standard flap, reverse flap, trunk reconstruction mammaplasty

Address for correspondence:

Daniel Yankov, MD, PhD

Division of Burns, Plastic, Reconstructive and Aesthetic

Surgery,

Department of Surgery,

Naval Hospital Varna,

Military Medical Academy of Sofia,

3 Hristo Smirnenski Street,

9010 Varna, Bulgaria

phone: 052-386426; mobile: 0884741262

e-mail:yankovplastics@yahoo.com

Received: December 09, 2012

Accepted: March 04, 2013

\section{INTRODUCTION}

Musculus latissimus dorsi was first used as a transposition flap for breast reconstruction by Tanzini (1896) and later on by D'Este (1912) (cited by 11). Nowadays, a wide range of pedicled flaps based on the vascular network of $m$. latissimus dorsi find application in plastic surgery for treatment of various defects on the head, neck, trunk, upper extremity, spine and lumbar regions. The muscle vascular anatomy allows its entire or partial free transfer to every part of the body. The flat shape and significant measures (mean of $25 \times 35 \mathrm{~cm}$ ) of $m$. latissimus dorsi represent a significant advantage against the alternative flaps when great areas of body surface should be covered. The size of the flap could be further increased by tissue expansion. Latissimus dorsi flap (LDF) ap- 
plication is also popular with lower rate of complications when compared with other reconstructive methods.

\section{Surgical anatomy of m. latissimus dorsi}

According to the muscular vascular anatomy classification of some authors (14), m. latissimus dor$s i$ is type $\mathrm{V}$ (one dominant and multiple secondary segmental pedicles). The dominant pedicle is presented by $a$. thoracodorsalis и $v v$. comitantes which are branches of $a$. subscapularis and v. subscapularis. The secondary pedicles are presented by two rows (medial and lateral) consisting of perforator branches of aa. intercostales posteriores and $v v$. intercostales posteriores as well as aa. lumbales and $v v$. lumbales. The length of the thoracodorsal pedicle can reach up to $8 \mathrm{~cm}$, and the diameter of the artery - up to 2,5 $\mathrm{mm}$. The artery enters the deep surface of the muscle in the posterior axilla around $10 \mathrm{~cm}$ bellow the humeral insertion of $m$. latissimus dorsi. The motor innervation of the muscle is delivered through $n$. thoracodorsalis (C6-C8).

\section{MATERIAL AND METHODS}

The study was conducted for the period between May 2003 and July 2011, in the Division of Burns, Plastic, Reconstructive and Aesthetic Surgery, Department of Surgery, Naval Hospital of Varna. A total of eight pedicled LDFs were used to correct tissue deficiency in separate regions of the trunk in seven patients (six females and one male aged from 38 to 67 years at a mean age of 51 years). Seven LDFs were designed to be transferred on their major pedicle, and one LDF - on its secondary vessels as a reverse flap. Four LDFs were applied for breast reconstructions, one - for treatment of post radiation wound after mastectomy, one - for covering the extensive defect of the anterior chest wall after toxic skin necrosis, one - for correction of post burn contracture in the region of axilla and one - for lumbar reconstruction after radical melanoma excision. Bilateral LDFs (one muscle and one skin-muscle) were applied in a female patient for breast reconstruction after anterior chest wall deformity caused by complications of hydrogel infiltration. All but one LDF were used as composite myocutaneous flaps.

\section{RESULTS}

The results were assessed on the basis of flap vitality during the early postoperative period, the late flap adaptation in the recipient area (at least six months after the surgery), donor site morbidity, and patient's satisfaction. Narrow partial flap necrosis was observed in the most distant edge of the largest skinmuscle flap used for anterior thorax reconstruction. Minor secondary intervention was sufficient to correct the problem. No total flap necrosis was encountered in any of the cases at all.

With respect to LDF transferred tissue volume, area surface, colour, elasticity and mobility, very good late results were registered in six patients. Additional reconstruction was necessary for a better aesthetic result in a female patient, however, she refused further surgery. There was no incident of donor wound seroma formation. No patient complained of shoulder functional impairment. Donor site scar depression was observed in one case only. All the patients claimed to be highly satisfied with the result from the intervention.

\section{Clinical case one}

A 38-year-old female patient was admitted for bilateral breast reconstruction because of deformity and soft tissue deficiency of the anterior chest wall. The disfigurement had been caused by destructive inflammation as a complication of simultaneous hydrogel removal and breast implants augmentation (Fig. 1). At the first stage, we reconstructed the right

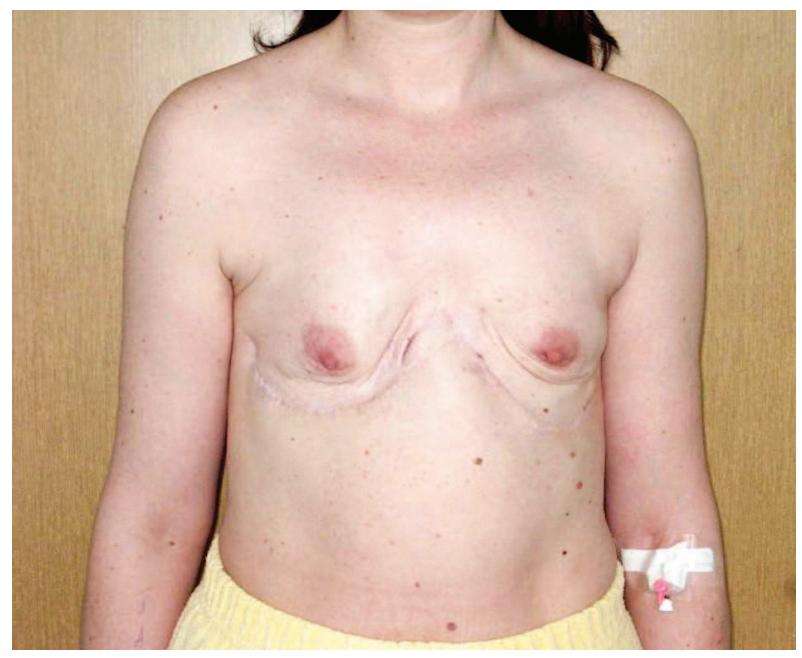

Fig. 1. Preoperative view of the deformity 


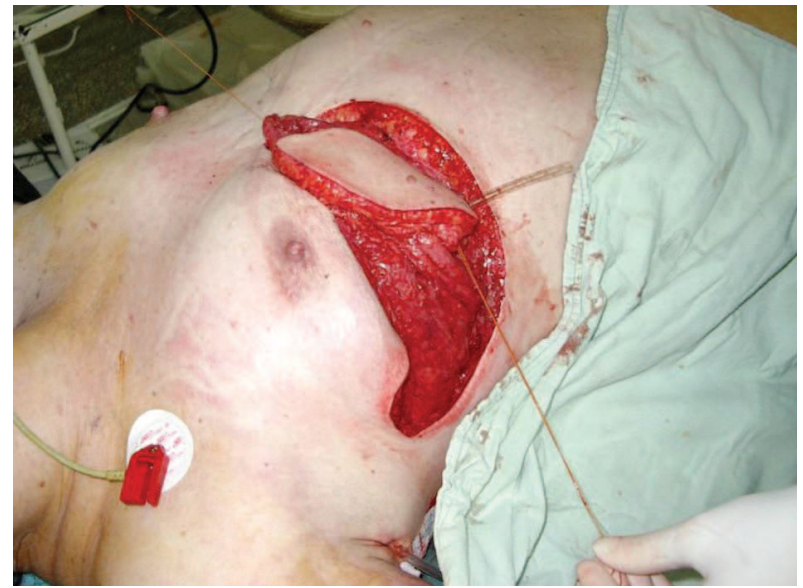

Fig. 2. Pedicled myocutaneous LDF for right breast reconstruction

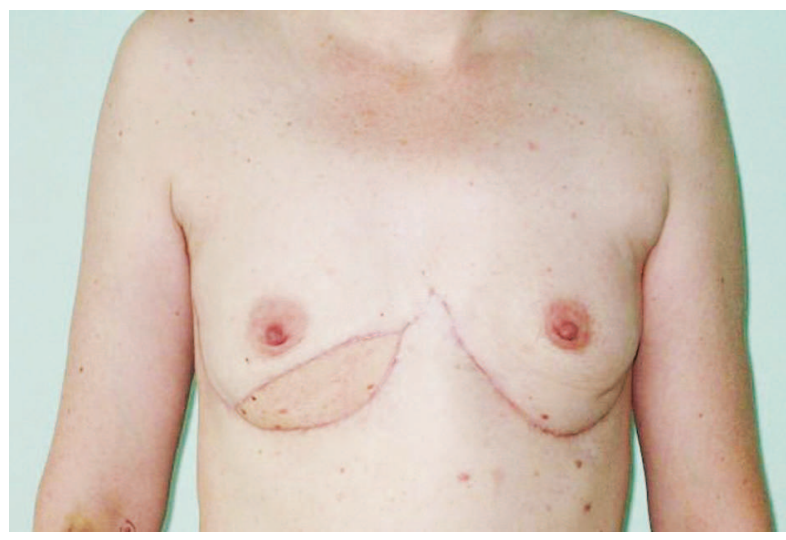

Fig. 3. Patient view after bilateral breast reconstruction with LDFreconstruction

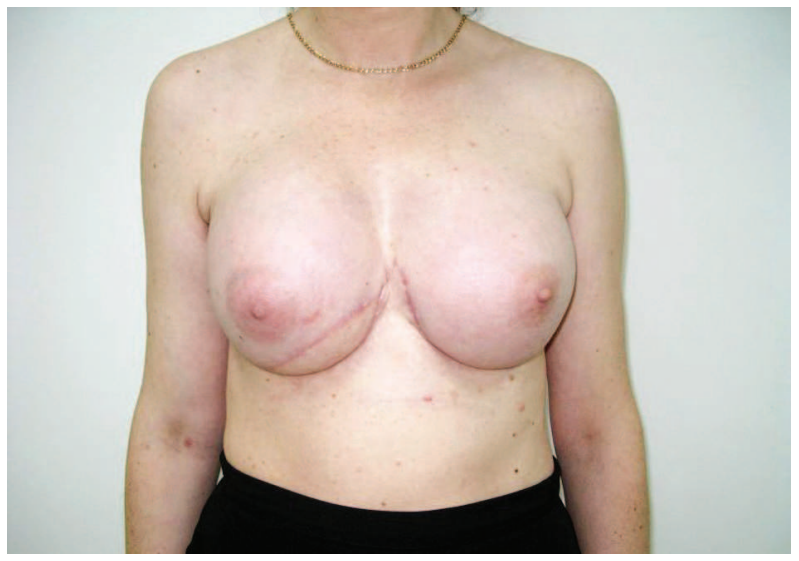

Fig. 4. Final result at one year after the silicone implants augmentation

breast by pedicled skin-muscle LDF and the left breast by muscle LDF only (Fig. 2). Because of the patient's desire for large-sized breast, two $650 \mathrm{~cm}^{3}$ expanders

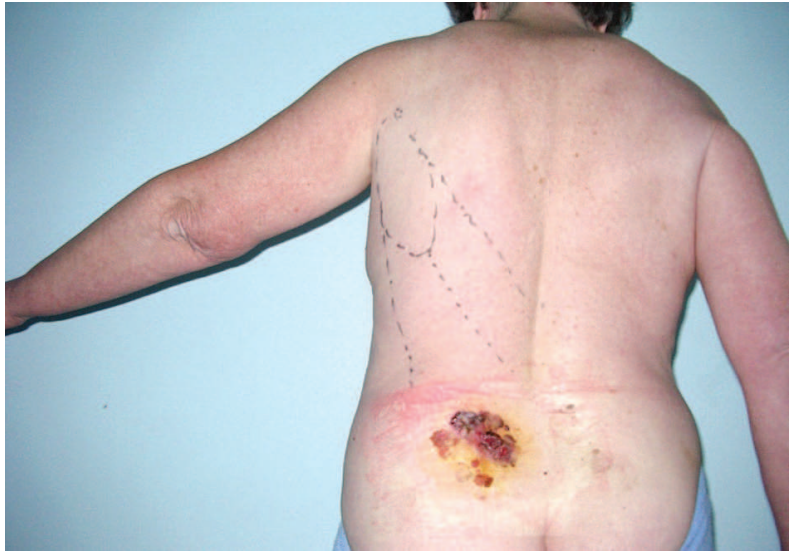

Fig. 5. Advanced MM in left lumbar region

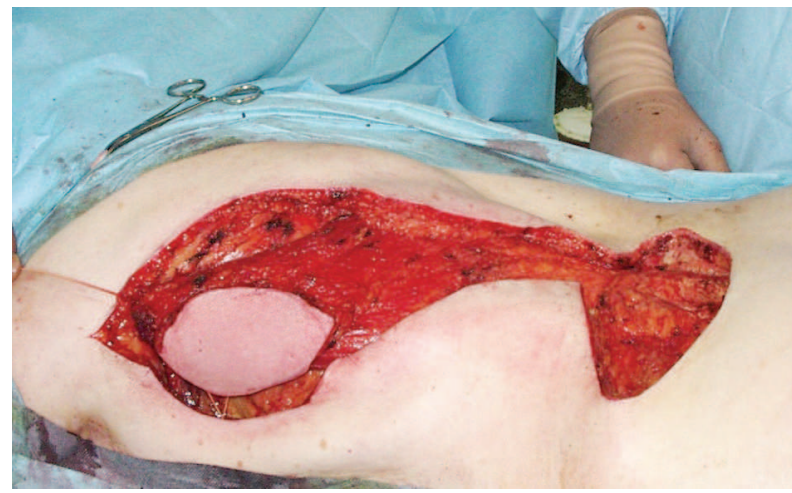

Fig. 6. Reverse LDF prepared for transfer to the defect from the excised tumour

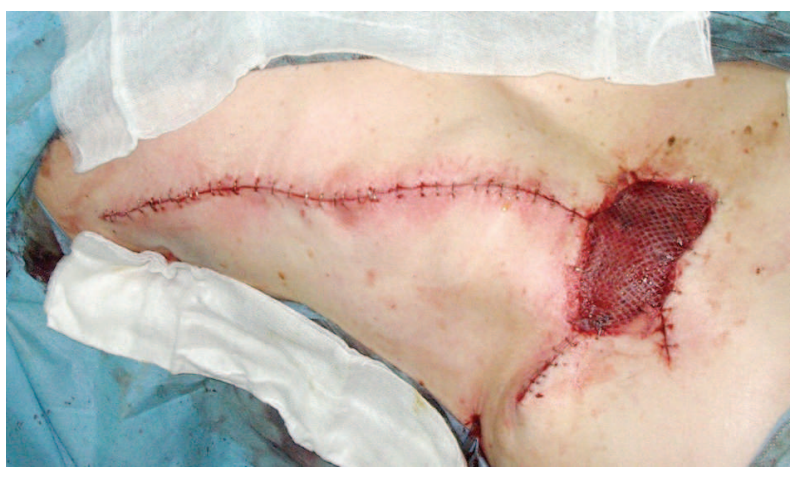

Fig. 7. LDF and free skin graft plasty at the end of the operation

were implanted bilaterally six months later on (Fig. 3). The third operation included replacement of the expanders with $600 \mathrm{~cm}^{3}$ anatomical silicone gel implants two months after the second intervention. During a three-year follow-up period (Fig. 4), no complications were observed and the patient declared her very high satisfaction with the result. 
Daniel Yankov, Yolanda Zayakova, Hristo Hristov et al.

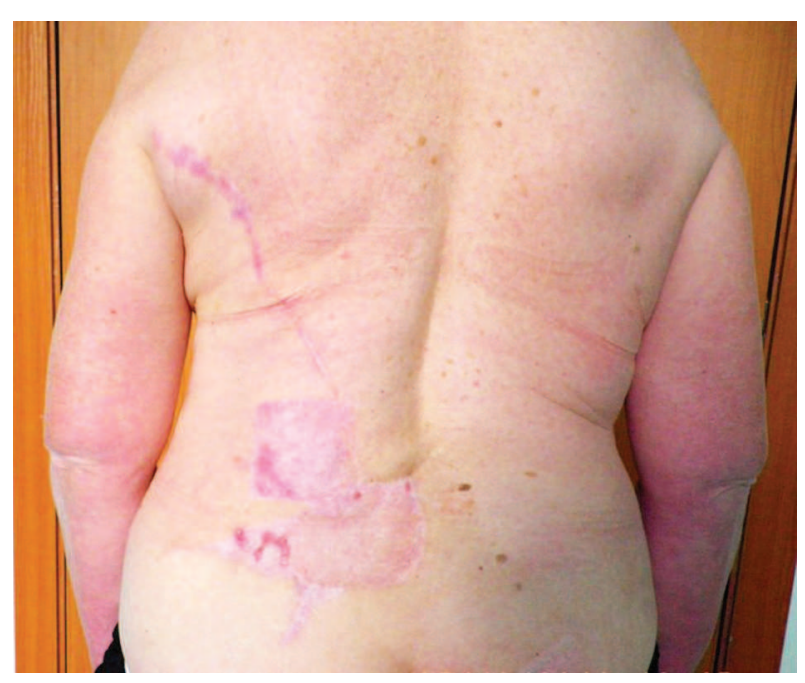

Fig. 8. Final result at six months after the surgery

\section{Clinical case two}

A 62-year-old female was admitted for surgical treatment of clinically proved advanced melanoma in the left lumbar region (Fig. 5). After the radical excision of the tumor, we applied reverse LDF to reconstruct the soft tissue defect (Fig. 6). LDF volume was increased by deepidermized skin island turned to the deep wound surface. The superficial muscle part of LDF was covered with a free skin graft (Fig. 7). Six months later on, LDF was well-adapted and no tumor recurrence was apparent at all (Fig. 8). The patient had no complains of left shoulder disability.

\section{DISCUSSION}

The pedicled LDF based on thoracodorsal vessels is pointed out as an effective method for both immediate and delayed breast reconstruction $(7,13)$. It is successfully used for reconstructive operations in the regions of head and neck $(2,3)$, back $(5,6,9)$ and upper extremity (16), too. In accordance with the individual needs of the reconstruction, LDF size can be further augmented by its preliminary expansion (5). The vascular anatomy of the muscle allows its movement as a reverse flap $(5,6,9)$. Jandali et al. (8) apply muscle-sparing latissimus dorsi myocutaneous flaps for the treatment of axillary hidradenitis in order to reduce the donor site morbidity. LlewellynBennett et al. (12) make use of fibrin sealant to avoid seroma formation at the donor site. Better aesthetic result at this area can be achieved by endoscopically assisted LDF harvesting (17).
Several studies analyze the rate of postoperative complications and conclude that LDF is a safe reconstructive method with insignificant risk for side effects and negative consequences $(1,4,10)$.

Based on the literature available and our own experience, we consider the following advantages of the pedicled LDF:

* flexibility - LDF's composition and dimensions are subject of individualization;

* applicable in three separate regions of the body;

* high biological resistance;

* suitable to cover large tissue defects;

* a low risk of functional deficit at the donor site, and

* applicable for functional plasty of the upper extremity.

The disadvantages of LDF include:

* risk of donor site seroma formation;

* contour deformity of the dorsum, and

* depressive cicatrix at the donor area when large myocutaneous LDF is harvested.

\section{CONCLUSION}

Our modest experience supports the common opinion about the effectiveness of the pedicled LDF in reconstructive surgery. We are well aware of the sense of mastering this surgical tool, in particular for dimensional reconstructions of chest and back regions. We also hope to have been helpful, exposing and sharing our clinical experience with this LDF application.

\section{REFERENCES}

1. Adams, W. P. Jr, A. H. Lipschitz, M. Ansari, J. M. Kenkel, R. J. Rohrich. Functional donor site morbidity following latissimus dorsi muscle flap transfer.- Ann. Plast. Surg., 53, 2004, No 1, 6-11.

2. Anastasov, K., P. Tepavicharova. Reconstruction of large facial and neck defects with skin-muscle flaps.- Khirurgiia (Sofiia), 42, 1989, No 1, 64-68 (in Bulgarian).

3. Aslan, I., Y. Süoğlu, B. Başaran, G. Hafız. The use of the latissimus dorsi myocutaneous flap in the reconstruction of complex head and neck defects.Kulak Burun Bogaz Ihtis Derg., 20, 2010, No 5, 226-231. 
4. Bonomi, S., F. Settembrini, A. Salval, C. Gregorelli, G. Musumarra, V. Rapisarda. Current indications for and comparative analysis of three different types of latissimus dorsi flaps.- Aesth. Surg. J., 32, 2012, No 3, 294-302.

5. Bostwick, J. 3rd, M. Scheflan, F. Nahai, M. J. Jurkiewicz. The "reverse" latissimus dorsi muscle and musculocutaneous flap: anatomical and clinical considerations.- Plast. Reconstr. Surg., 65, 1980, No 4, 395-399.

6. Hallock, G. G. Reconstruction of posterior trunk defects.- Semin. Plast. Surg., 25, 2011, No 1, 78-85.

7. Hammond, D. C. Latissimus dorsi flap breast reconstruction.- Plast. Reconstr. Surg., 124, 2009, No 4, 1055-1063.

8. Jandali, S., M. N. Mirzabeigi, J. Fosnot, D. W. Low. Thoracodorsal artery perforator flaps and musclesparing latissimus dorsi myocutaneous flaps for the treatment of axillary hidradenitis.- Ann. Plast. Surg., 69, 2012, No 4, 371-375.

9. Kotti, B., O. Jaidane, J. Ben Hassouna, K. Rahal. The "reverse" latissimus dorsi flap for large lower lumbar defect.- Case Rep. Surg., 2012: 964625. doi: $10.1155 / 2012 / 964625$.

10. Laitung, J. F., F. Peck. Shoulder function following the loss of latissimus dorsi muscle.- Br. J. Plast. Surg., 38, 1985, No 3, 375-379.

11. Lassen, M., C. Krag, I. M. Nielsen. The latissimus dorsi flap. An overview.- Scand. J. Plast. Reconstr. Surg., 19, 1985, No 1, 41-51.
12. Llewellyn-Bennett, R., R. Greenwood, J. R. Benson, R. English, J. Turner, Z. Rayter, et al. Randomized clinical trial on the effect of fibrin sealant on latissimus dorsi donor-site seroma formation after breast reconstruction.- Br. J. Surg., 99, 2012, No $10,1381-1388$.

13. Losken, A., C. S. Nicholas, X. A. Pinell, G. W. Carlson. Outcomes evaluation following bilateral breast reconstruction using latissimus dorsi myocutaneous flaps.- Ann. Plast. Surg., 65, 2010, No 1, 17-22.

14. Mathes, S. J., F. Nahai. Reconstructive surgery: principles, anatomy, and technique. Vol. 1. London, Churchill Livingstone, 1997, 565-616.

15. Mimoun, M., M. Chaouat, B. Lalanne, S. Smarrito. Latissimus dorsi muscle flap and tissue expansion for breast reconstruction.- Ann. Plast. Surg., 57, 2006, No 6, 597-601.

16. Stevanovic, M., F. Sharpe, V. D. Thommen, J. M. Itamura, S. B. Schnall. Latissimus dorsi pedicle flap for coverage of soft tissue defects about the elbow.- J. Shoulder Elbow Surg., 8, 1999, No 6, 634-643.

17. Veir, Z., A. Dujmović, M. Duduković, D. Mijatović, B. Cvjeticanin, M. Veir. Endoscopically assisted latissimus dorsi flap harvesting and breast reconstruction in young female with Poland syndrome.- Coll. Antropol., 35, 2011, No 4, 1303-1305. 